\section{Abstractions}

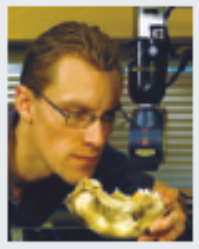

FIRST AUTHOR

In studying mammalian

evolution, teeth are a

scientist's most valuable

fossil find. Alistair Evans, a

postdoc at the University

of Helsinki's Institute of

Biotechnology in Finland,

and his collaborators applied geographic

information system (GIS) data-analysis tools

to the dental landscape. GIS is typically used

to an alyse geographically referenced data-

often obtained from aerial photography

or satellite imagery. By analysing athree-

dimensional image of an entire row of

teeth, rather than comparing individual

teeth, Evans and his colleagues were able

to estimate an organ ism's entire food-

processing capacity. On page 78 theydetail

similarities among 81 species of carnivorans

and rodents. So what dictates this similarity?

Why have exhaus tive quantitative

comparisons of tooth shapes not been done before?

An alysis has previously been limited to more straightforward measurements such as individual tooth and crest sizes. Usually, techniques compare aspects of tooth shape that are homologous between species. We've tried to develop a technique that circumvents the need to look at similar teeth by analysing tooth shape as a whole.

This is not a typical use of GIS. What made you think of using it?

When you spend so longlooking at teeth, you start to see shapes of mountains, valleys, hills and crests. Many tools used in geology and geographycan be directly applied to other shapes, including those of teeth.

You revealed a surprising similarity between thegroups - how can this be explained? Wemeasured dental complexity as a function of the number of features on teeth, such as cusps and blades of many possible shapes. A herbivorous animal has more complex teeth than a strict carnivore. But surprisingly, the range of complexity values recorded for four of the fivediet types studied - the exception being sole meat-eaters - were very similar between the two taxonomic groups. There seem to be some scale-independent and phylogenyindependent forces that dictate complexity of tooth shape depending on diet. What you are eating is much more important to tooth complexity than your genetic heritage.

\section{What's next?}

Weplan to apply this technique to other species. We'd like to study multituberculates - a major branch of mammals that became extinct after having thrived for 100 million years. With no living relatives and no idea what they ate, this is a group that people have been trying to interpret for a long time.
MAKING THE PAPER

Leslie Vosshall

\section{Researchers work towards throwing mosquitoes off the scent.}

Mosquitoes track their victims by following carbon dioxide trails from their prey's breath. Like most insects, mosquitoes detect this gas with great sensitivity - something humans cannot do. To Leslie Vosshall at the Rockefeller University in New York this capability "was a fascinating unsolved problem".

Scientists had long been aware that most insects can detect $\mathrm{CO}_{2}$, but they knew little about the molecules involved in this process. Identification of mosquitoes' $\mathrm{CO}_{2}$ receptors could help scientists develop compounds to throw the insects off their human trail, thereby preventing the spread of mosquito-borne diseases such as malaria and West Nile virus.

Vosshall became interested in insect $\mathrm{CO}_{2}$ detection in 2004 when she was finishing her postdoc on the fruitfly Drosophila in Richard Axel's laboratory at Columbia University, New York. When this insect nears something that gives off $\mathrm{CO}_{2}$, it quickly turns away. Work by Axel's group and
"The technology for making

targeted mutants in not as mature for flies as for mice. We were lucky that we got one mutant after one year." would use a pair of receptors to detect $\mathrm{CO}_{2}$. The only clue they had to these receptors' identity was the protein $\mathrm{Gr} 21 \mathrm{a}$, which is expressed on $\mathrm{CO}_{2}$-detecting neurons. So Jones searched for another Drosophila protein that would co-localize with $\mathrm{Gr} 21 \mathrm{a}$, which led him to Gr63a.

The next hypothesis was that the genes encoding Gr21a and Gr63a would be conserved in other insects, demonstrating that they perform a critical function. A screen for homologues in the mosquito Anopheles gambiae, one of the species that carry malaria, found two matches (see page 86).

The next step was the most challenging. To show that Gr21a and Gr63a are necessary for detecting $\mathrm{CO}_{2}$, Vosshall and Jones needed to knock one or both genes out and show that the flies could not detect the gas. "The technology for making targeted mutants in not as mature for flies as for mice. There is an element of luck involved," says Vosshall. "We were lucky that we got one mutant after one year." Consistent with their third hypothesis, their mutant fly that lacked $\mathrm{Gr} 63 a$ did not avoid $\mathrm{CO}_{2}$.

"The study was done very sequentially," says Vosshall. "It was one of the simplest studies done in my lab." But the work was not without surprises. The team found that both Gr21a and Gr63a are membrane proteins. In vertebrates, gas receptors typically John Carlson at Yale University in New Haven, Connecticut, determined that one neuronal type in Drosphila antennae is responsible for this avoidance behaviour. In addition, Axel's group found that the protein $\mathrm{Gr} 21 \mathrm{a}$ is expressed specifically on the $\mathrm{CO}_{2}$-detecting neurons.

${ }^{\alpha}$ These were the building blocks for my work," recalls Vosshall. Once she had established her own laboratory, Vosshall and postdoc Walton Jones developed possible hypotheses for finding the elusive $\mathrm{CO}_{2}$ receptors in Drosophila, and their team started considering approaches to test it. They knew that in Drosophila two distinct proteins always team up to detect a specific odour. From this they proposed that Drosophila reside inside cells. "It is possible that in vertebrates the receptors for carbon dioxide are also membrane proteins," says Vosshall. But for the moment she will be turning her attention not to vertebrates but back to mosquitoes.

Vosshall and her colleagues next hope to show that the homologous receptors identified in mosquitoes also function as $\mathrm{CO}_{2}$ detectors. To do this, they can either carry out genetic manipulations directly in mosquitoes, which is tricky to do, or use Drosophila or frog oocytes as 'synthetic mosquitoes.' They will then be able to start testing different compounds to block the receptors and keep mosquitoes away from their food source.

\title{
KEY COMMUNICATION
}

For some time Saturn's moon

Titan has been proposed to have lakes of liquid methane. Radar imaging signals from the Cassini spacecraft's 'flyby' on 22 July 2006 hint that these proposals might be correct (see page 61). And a real-time e-mail that began during the flyby helped a group of researchers to piece the data together into strong evidence for the existence of lakes, says Ellen Stofan, a geologist at University College London, UK.
When the data began to flow, 38 scientists from around the world immediately weighed in with their opinions on an e-mail 'exploder' that allowed them to discuss the spacecraft's observations in real time. The group included geologists, engineers and radar experts, allowing the data to be simultaneously evaluated from various perspectives. The contributions of different fields to this analysis were crucial to the group's success, says
Stofan. "Everyone's expertise came into play."

So communications technology not only brought Cassini's observations to Earth, but also allowed them to be analysed in a host of locations almost immediately. "If you had asked me ten years ago whether it would be possible to study this sort of science bye-mail rather than by being in one room together, I would have said 'No way!"'s says Stofan. 